\title{
Postnephrectomy Arteriovenous Fistula: A Case Report
}

\author{
Shigeru Amitani, Kenkichi Miyahara,* Hiroshi Miyanohara, Kazuhiko Nakamura, Terukatsu Arima, \\ Yasuo Morishita** and Akira TAIrA**
}

\begin{abstract}
We report a 57-yr-old woman with severe cardiac failure secondary to postnephrectomy arteriovenous fistula which was successfully removed. A review of the literature shows the rarity of this complication; only 72 cases have been reported in the world literature including 6 cases (including the present case) from Japan. Surgical intervention is generally the treatment of choice from a fistula and provides satisfactory results for cardiac failure which is the major complication of this fistula. A characteristic bruit was observed in all reported cases. Therefore, nonsurgical closure by percutaneous embolization for a small sized shunt may be possible if early diagnosis is obtained by careful auscultation of the loin.
\end{abstract}

(Internal Medicine 31: 98-101, 1992)

Key words: nephrectomy, mass ligation, cardiac failure, auscultation

\section{Introduction}

Postnephrectomy arteriovenous fistula is an uncommon complication. From the first report by Hollingsworth (1). 66 cases were reported in the world literature up to 1989 (2). In a subsequent search an additional 5 cases were reported ( $3-7)$; thus, the present case is the 72 nd in the world literature and the 6th in the Japanese literature. In this paper, we emphasize the importance of early diagnosis by careful auscultation and early treatment before the development of cardiac failure in this disease.

\section{Case Report}

A 57-yr-old housewife was admitted with a 1-month history of dyspnea in June 1987. On admission, dilated jugular veins, edematous lower extremities and orthopnea were present. Fifteen years previously, the patient underwent right nephrectomy for renal stones, and had no particular postoperative complications. In 1984, cardiomegaly was accidentaly detected, but she had no medical treatment because she was free from subjective symptoms.

A grade $2 / 6$ systolic ejection murmur was heard at the apex, and a grade $5 / 6$ bruit without thrill in the right flank and lumbar fossa. The blood pressure was $140 /$
$80 \mathrm{mmHg}$, and pulse was irregular with a rate of $78 / \mathrm{min}$. Erythrocyte level of $3.85 \times 10^{6} / \mathrm{mm}^{3}$, hemoglobin, $11.7 \mathrm{~g} / \mathrm{dl}$ and hematocrit $34 \%$ indicated slight anemia. No abnormal data were found in biochemical examinations. Chest X-ray film showed cardiothoracic ratio (CTR) of $80 \%$, and congestion of both lower lung fields (Fig. 1a). Electrocardiogram demonstrated a sinus rhythm with sporadic ventricular premature beats. Echocardiogram revealed slight hypertrophy of the left ventricular wall, and a markedly enlarged left ventricular cavity and left atrium. All valves were intact. The left ventricular ejection fraction was 0.75 , and no left ventricular asynergy was observed. On phonocardiogram, abdominal bruit showed a typical continuous murmur. For the cardiac failure, diuretics were given and digitalization was performed. Then, her subjective symptoms disappeared and the CTR showed marked improvement on the 13th hospital day. So, for the purpose of early definite diagnosis, cardiac catheterization and angiography were performed.

Venous oxygen saturation of the inferior vena cava below and above the right renal vein were 62 and $95 \%$, respectively. Cardiac catheterization data showed a leftto-right shunt rate of $81 \%$ and cardiac index of $10 \mathrm{l} / \mathrm{min} /$ $\mathrm{m}^{2}$ (Table 1). Abdominal aortography revealed a dilated right residual renal artery suggesting aneurysm, and a

From The Second Department of Internal Medicine, ** The Second Department of Surgery, Faculty of Medicine, Kagoshima University, Kagoshima and * Cardiovascular Division, Shinkyo Hospital, Kagoshima

Received for publication August 23, 1990; Accepted for publication March 30, 1991

Reprint requests should be addressed to Shigeru Amitani, MD, The Second Department of Internal Medicine, Faculty of Medicine, Kagoshima University, 8-35-1 Sakuragaoka, Kagoshima 890, Japan 


\section{Postnephrectomy A-V Fistula}

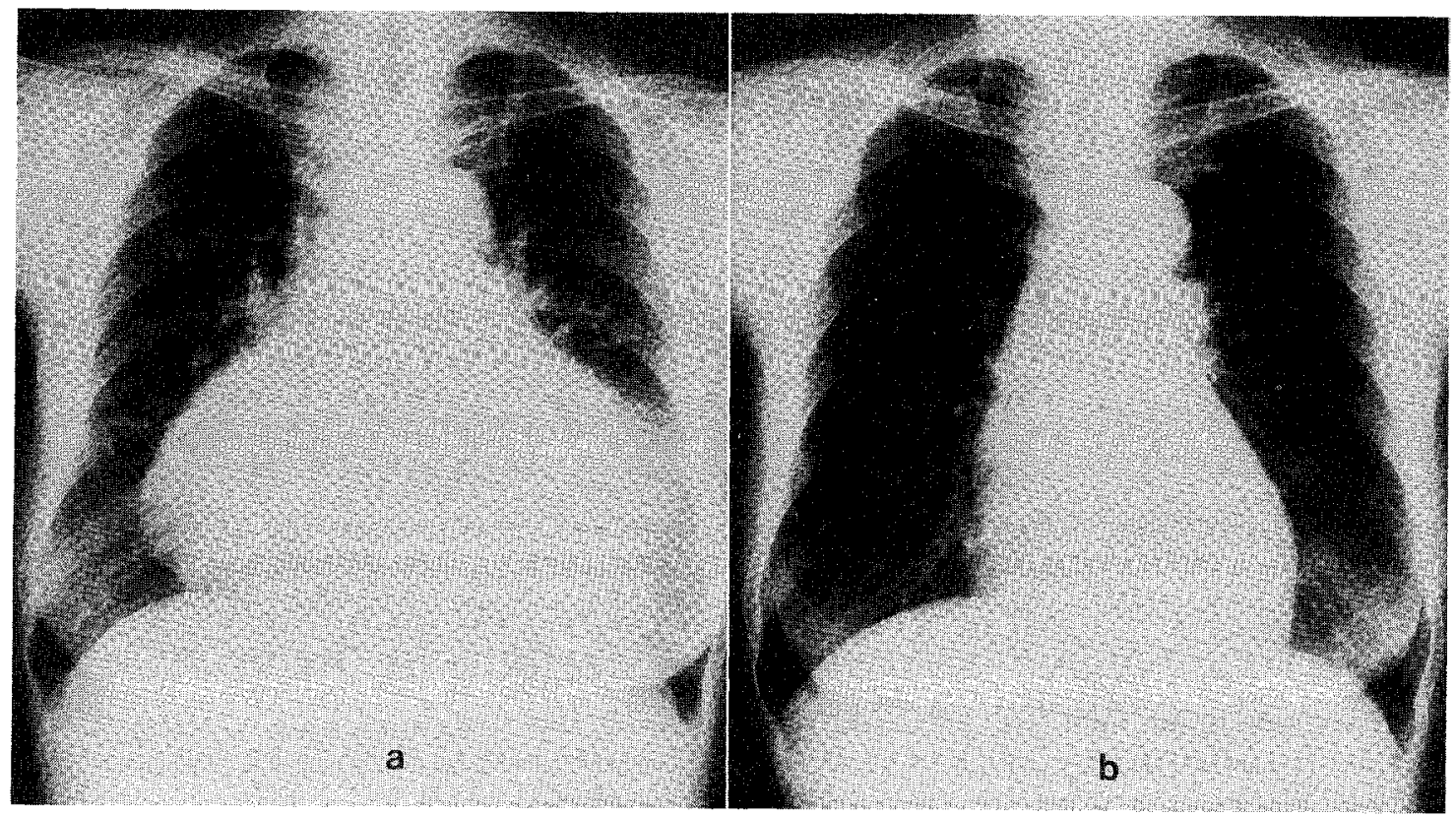

Fig. 1. Chest $\mathrm{X}$-ray photograms. a) On admission remarkable cardiomegaly was revealed $(\mathrm{CTR}=80 \%)$. Congestion was observed in the lower lung field on both sides. b) At 2 months after operation, the cardiac silhouette showed a marked decrease $(\mathrm{CTR}=48 \%)$.

Table 1. Results of Cardiac Catheterization

\begin{tabular}{|c|c|c|}
\hline & Pressure (mmHg) & $\mathrm{O}_{2}$ saturation $(\%)$ \\
\hline IVC lower & - & 61.8 \\
\hline upper & - & 94.6 \\
\hline SVC & - & 68.2 \\
\hline RA & $\mathrm{m} 1$ & 90.1 \\
\hline RV & $24 / /_{\mathrm{EDP}} 4$ & 92.7 \\
\hline PA & $24 / 7 \quad$ m 14 & 92.3 \\
\hline $\mathrm{PC}$ & m 8 & - \\
\hline LV & $120 /{ }_{\mathrm{EDP}} 5$ & - \\
\hline $\mathrm{AO}$ & $120 / 70 \quad$ m 95 & 97.6 \\
\hline
\end{tabular}

$\mathrm{Q}_{\mathrm{s}}=2.541 / \mathrm{min} / \mathrm{m}^{2}, \mathrm{Q}_{\mathrm{p}}=13.5 \mathrm{l} / \mathrm{min} / \mathrm{m}^{2}, \mathrm{Q}_{\mathrm{p}} / \mathrm{Q}_{\mathrm{s}}=5.31$ $\mathrm{L}-\mathrm{R}$ shunt $=11.01 / \mathrm{min} / \mathrm{m}^{2}, \mathrm{~L}-\mathrm{R}$ shunt rate $=81.2 \%$

IVC, inferior vena cava; SVC, superior vena cava; RA, right atrium; $\mathrm{RV}$, right ventricle; $\mathrm{PA}$, pulmonary artery; $\mathrm{PC}$, pulmonary capillary; LV, left ventricle; $\mathrm{AO}$, aorta; $\mathrm{m}$, mean; EDP, end diastolic pressure.

communication between the right renal artery and the inferior vena cava (Fig. 2).

Under the diagnosis of postnephrectomy arteriovenous fistula, surgical treatment was performed to close the fistula in August 1987. At operation, the fistula $(8 \mathrm{~mm}$ in diameter) was totally excised (Fig. 3). The residual renal artery was doubly ligated at its proximal point to the abdominal aorta. Her postoperative course was uneventful with disappearance of all symptoms. The CTR improved to $48 \%$ (Fig. 1b), and cardiac index became normalized, with a value of $4.31 / \mathrm{min} / \mathrm{m}^{2}$ after surgery.

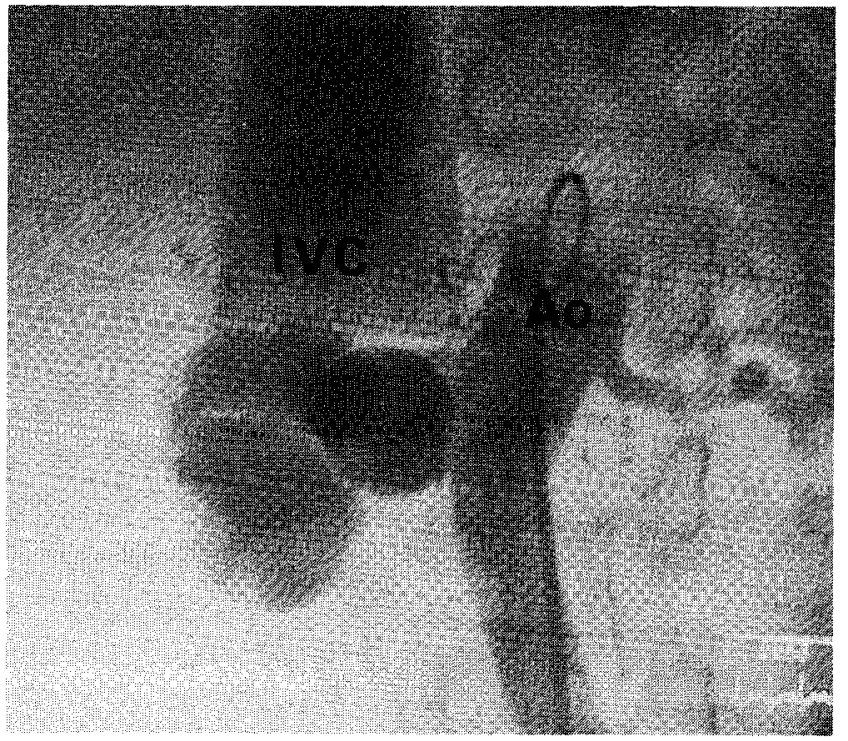

Fig. 2. Abdominal aortography. The right residual renal artery is enlarged, forms a large aneurysm, and is directly connected with the inferior vena cava which is enlarged due to fistula. IVC, inferior vena cava; Ao, abdominal aorta.

\section{Discussion}

Main causative factors in the development of postnephrectomy arteriovenous fistula include mass ligation of the renal pedicle (8), hemorrhage (9) and infection $(10,11)$. These factors produce crash and necrosis of the vascular wall in the stump of the renal pedicle, finally resulting in the formation of fistula (12). Seventy percent 


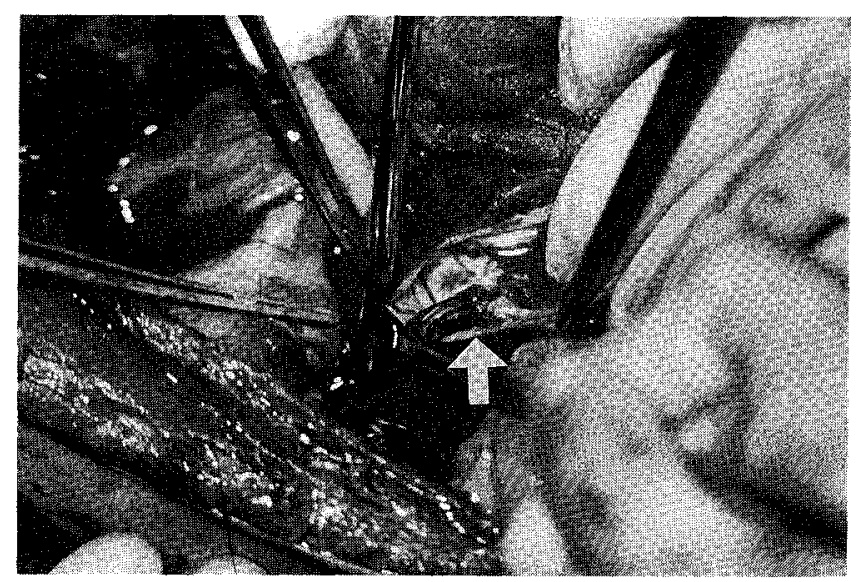

Fig. 3. Surgical findings. The fistula (arrow), with $8 \mathrm{~mm}$ in diameter, was revealed on the inside of incised inferior vena cava.

of reported cases occur in the right side. The difference in occurrence between renal sides is probably due to an anatomical reason between the renal veins (13). However, there are a few reports (14) in which the fistula occurred in the left side of patients who underwent bilateral nephrectomies. The mechanism for the high frequency of location in the right side has not been clarified yet.

With peripheral arteriovenous fistula, cardiac failure is generally produced only when the shunt ratio exceeds $30 \%$ of cardiac output (15). The mechanisms are considered to be the following: once a fistula has been formed, the abnormal communication produces a left-toright shunt due to the decrease in peripheral vascular resistance. Consequently, cardiac output rises because of increased heart rate and stroke volume. Then the circulating blood flow increases compensatively. This in turn increases shunted flow, causing progressive increment of the diameter of the fistula. Thus, a vicious cycle is created, finally leading to compensative cardiac failure (16).

As in the present case, in more than $70 \%$ of the previously reported cases, cardiac failure was observed as the initial symptom, and the diagnosis of fistula formation was obtained after cardiomegaly or cardiac failure had developed. In only a few cases, the fistula was accidentaly detected by the presence of a bruit; these cardiac failures occurred from 3 months to $35 \mathrm{yr}$ after postnephrectomy arteriovenous fistula. But the duration between nephrectomy and fistula formation is not evident in the literature. Pate et al (17), in a study of 13 cases of traumatic arteriovenous fistula, reported an average duration of approximately $16.3 \mathrm{yr}$ from fistula formation to the onset of cardiac failure. Holman (16) also described that the heart tolerance of the fistula was extremely long inspite of its high output and its situation on vessels neighboring the heart. On the other hand, in this disease, characteristic bruit was present in all cases reported and was observed even in patients without cardiomegaly or cardiac failure. This strongly suggests that careful postoperative auscultation should always be carried out over a wound area to detect the fistula before cardiomegaly or cardiac failure develops.

The treatment must accomplish closure of the arteriovenous communication. Until recent years, surgery was the only treatment available. With the development of embolization technique, nonsurgical closure of such fistulas is an option $(4,7,14)$. Nonsurgical embolization may be the treatment of choice only at the early stage with a small sized-shunt or for patients whose general condition and cardiac status are poor and represent a high operative risk.

In conclusion, as a bruit is the earliest sign in patients with arteriovenous fistula after nephrectomy, we emphasize that auscultation of the lumbar fossa should be a routine part of follow-up in every nephrectomized patient and that surgical or nonsurgical treatment is recommended before the development of cardiovascular decompensation.

\section{References}

1) Hollingsworth EH. Arteriovenous fistula of the renal vessels. Am J Med Sci 188: 399, 1934.

2) Shida T, Gan K, Shio K, Takemura Y. A case of postnephrectomy arteriovenous fistula. Jpn J Surg 19: 738, 1989.

3) Herman SD, Radecki PD, Friedeman AC, Caroline DF, Ramchandani P, Marmon LM, Grosh JD. Postnephrectomy pseudoaneurysm with arteriovenous fistula. Urol Radiol 9: 225, 1988.

4) Courtheoux P, Maiza D, Mani J, Mercier V, Theron J. Postnephrectomy arteriovenous fistula of the renal pedicle treated with detachable balloons: A case report. Cardiovasc Intervent Radiol 11: 340, 1988.

5) Malco AM, Larranaga JR, Vaquero $C$, Rodriguez S, Samos RF. Postnephrectomy arteriovenous fistula. J Cardiovasc Surg 29: $491,1988$.

6) Uematsu I, Koyama K, Ohuchi A, Itoh K, Kagawa K. Postnephrectomy arteriovenous fistula. Surg Diag Treat 41: 485, 1979 (in Japanese).

7) Saita H, Ohyama C, Higa T, Tohyama K, Nakada S. Postnephrectomy arteriovenous fistula treated by renal arterial embolization. Jpn J Clin Urol 41: 1061, 1987 (in Japanese).

8) Goldstein AG, Delauentis DA, Schwartz AJ. Postnephrectomy arteriovenous fistula. J Urol 98: 44, 1967.

9) Vick B, Nelson D, Cordell R. Postnephrectomy arteriovenous fistula. Am J Surg 111: 262, 1966.

10) Lacombe $M$, Renal arteriovenous fistula following nephrectomy. Urology 25: 13, 1985.

11) Gokarn A, Swinney J. Arteriovenous aneurysm of the renal artery after nephrectomy. Br J Urol 34: 15, 1962.

12) Yeates WK. Postnephrectomy arteriovenous fistula. Proc Roy Soc Med 60: 112, 1967.

13) Ogasawara $H$, Sakamoto $S$, Kobayashi $T$, et al. Secondary cardiac disease due to postnephrectomy arteriovenous fistula. Report of a case and review of literature. Kokyu to Junkan 33: 945, 1985 (in Japanese).

14) Castaneda-Zuniga WR, Tadavarthy SM, Murphy W, Beranek I, Amplatz K. Nonsurgical closure of large arteriovenous fistulas. J Am Med Assoc 236: 2649, 1976.

15) Nakamura $T$, Katahira $T$, Okamura $S$, et al. A case with congestive heart failure and dilated forearm arteriovenous dialysis 


\section{Postnephrectomy A-V Fistula}

fistula. Shinzo 21: 882, 1989 (in Japanese).

16) Holman E. Abnormal arteriovenous communications. Great variability of effects with particular reference to delayed development of cardiac failure. Circulation 32: 1001, 1965.
17) Pate JW, Sherman RT, Jackson T, Wilson H. Cardiac failure following traumatic arteriovenous fistula. A report of fourteen cases. J Trauma 5: 398, 1965. 